\title{
Medication Overuse Headache: A Trap for the Headache Patients
}

\author{
RAHMANA, HABIB R, BHOWMIK NB, HAQUE A
}

\begin{abstract}
Summary
Medication Overuse Headache (MOH) was previously termed analgesic rebound headache, drug-induced headache, and medication-misuse headache. It is not a primary headache but frequently coexists with primary chronic daily headache. All acute symptomatic medications used to treat headaches have the potential for causing $\mathrm{MOH}$. Highest with opioids, butalbital-containing combination analgesics, and aspirin/ acetaminophen/caffeine combinations. The development is typically preceded by an episodic headache disorder, usually migraine or tension-type headache, that has been treated with frequent and excessive amounts of acute symptomatic
\end{abstract}

\section{Background}

Some migraine patients fall into a trap by overusing the medications they take when they get their headaches, ending in a downward spiral of daily or near-daily headaches for which their medications become less and less effective. This condition is called medication overuse headache. It has also been termed analgesic rebound headache, drug-induced headache, and medication-misuse headache. Although not a primary type of chronic daily headache, $\mathrm{MOH}$ deserves proper coverage since it frequently coexists with primary headache. ${ }^{1,2}$ After successful MOH treatment, preventive medication for the underlying primary disorder have a greater chance for success. ${ }^{3}$

\section{Pathophysiology}

Available evidence suggests all drugs used for the acute symptomatic treatment of headache can cause $\mathrm{MOH}$ in

Rahman A, Habib R, Bhowmik NB, Haque A, Department of Neurology, Bangladesh Institute of Research and Rehabilitation in Diabetes, Endocrine and Metabolic Disorders, 122 Kazi Nazrul Islam Avenue, Shahbag, Dhaka.

Address for correspondence: Dr. Rahman A, Department of Neurology, Bangladesh Institute of Research and Rehabilitation in Diabetes, Endocrine and Metabolic Disorders, 122 Kazi Nazrul Islam Avenue, Shahbag, Dhaka. Email: aminurdr@gmail.com

Received: 12 March, 2013

Accepted: 09 July, 2013 medications. The diagnosis is based upon clinical impression. A history of analgesic use averaging more than two to three days per week in association with chronic daily headache is suggestive. The diagnosis is made when the pattern of frequent headaches fulfills the diagnostic criteria for МOH. The basic steps in the management: Patient education, withdrawal of the offending medication, bridge (transitional) therapy, establishment of a headache treatment regimen covering acute and preventive care, follow up and relapse prevention.

(Birdem Med J 2013; 3(2): 94-98)

primary headache disorders. ${ }^{4,5,6}$ The precise mechanisms that lead to $\mathrm{MOH}$ are still uncertain.

\section{Genetic predisposition}

Various studies and clinical observations suggest that $\mathrm{MOH}$ is restricted to individuals who already have other headache disorders ${ }^{4}$. Furthermore, $\mathrm{MOH}$ does not develop de novo in individuals with no previous headache history. ${ }^{5}$

In a study of 103 patients using daily analgesics for arthritic pain but not for headache, only eight patients (7.6 percent) had chronic daily headache, each of whom reported a previous history of episodic migraine. ${ }^{6}$ Patients with migraine and tension-type headache seem to have the highest potential for $\mathrm{MOH} .{ }^{7}$ However, $\mathrm{MOH}$ has also been described in cluster headache ${ }^{8}$ and in hemicrania continua. ${ }^{9}$

\section{Central sensitization}

Investigations demonstrating facilitation of trigeminal pain processing in patients with chronic headache have suggested that central sensitization, the same process that occurs in migraine, could lead to $\mathrm{MOH} .{ }^{7}, 10$ In humans, chronic exposure to triptans and other analgesics could lead to down regulation of serotonin receptors. ${ }^{4,11,12}$

\section{Biobehavioral factors}

It has been proposed that $\mathrm{MOH}$ is a biobehavioral disorder. ${ }^{13}$ Some patients may have addictive disease, 
characterized by compulsive drug seeking and drug taking behavior despite negative consequences, other patients may use opiates or other drugs with sedative/ anxiolytic effects to treat both pain and a coexistent anxiety disorder. ${ }^{13}$ In a prospective population-based longitudinal study of 32,067 adults from Norway, subjects using analgesics daily or weekly at baseline had a significantly increased risk of chronic pain 11 years later compared to those who never used analgesics. ${ }^{14}$

\section{Epidemiology}

The prevalence of $\mathrm{MOH}$ in the general population is approximately 1 percent, ${ }^{15}$ and is higher in women than in men. ${ }^{10,19}$ In a population-based study of over 49,000 subjects from Norway, the prevalence of chronic headache with analgesic overuse lasting three months or longer was 0.9 percent overall ${ }^{20}$ In two smaller population studies from Spain, the prevalence of medication overuse headache was approximately 1.5 percent, ${ }^{18,21}$ with a female to male ratio of $17: 1 .{ }^{21}$ Among patients who are seen at specialized headache centers, the prevalence of $\mathrm{MOH}$ is much higher, ranging from 4 to 80 percent. ${ }^{4,22,23}$

\section{Causal medications}

All acute symptomatic medications used to treat headaches have the potential for causing $\mathrm{MOH}^{4}, 5,6$ Based upon the literature and clinical experience, the risk appears to be highest with opioids, butalbital (Barbiturate with an intermediate duration of action)containing combination analgesics, and aspirin/ acetaminophen/caffeine combinations. ${ }^{10,24}$ The evidence supporting these risks is illustrated by the following reports: A 2008 review of clinic-based and population studies found that, for opiates, the increased risk was more pronounced in men, and the critical dose of exposure was approximately eight days a month. ${ }^{25,26}$ In a 2004 report from a tertiary headache center in New York of 169 patients who were followed in the last five years of the study (i.e., the triptan era), the drugs most often associated with $\mathrm{MOH}$ included the following (Figure:1). ${ }^{27}$

In a 2002 prospective German study of 98 patients with $\mathrm{MOH}$, including 70 patients with migraine as the underlying primary headache type, overuse of triptans led to $\mathrm{MOH}$ sooner than overuse of ergots or analgesics, and did so at a lower frequency of use. ${ }^{28}$ The mean

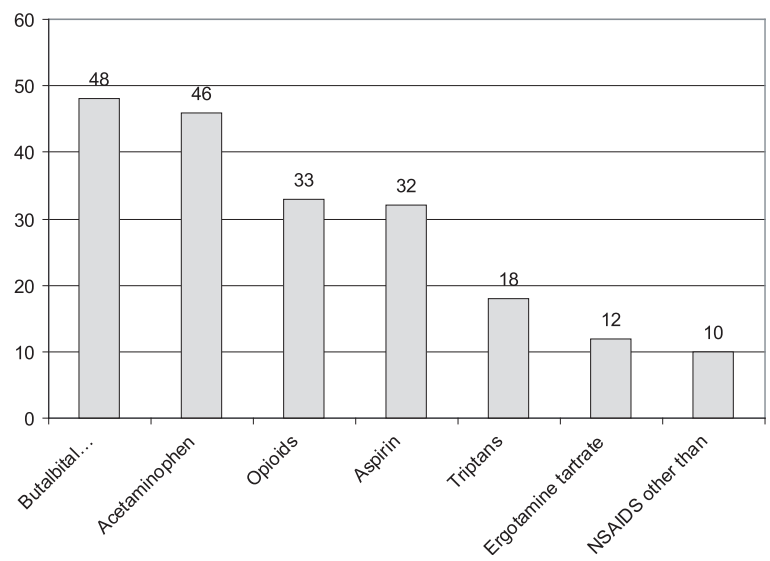

Fig.-1: Drugs associated with $\mathrm{MOH}$.

interval until onset of $\mathrm{MOH}$ was shortest for triptans (1.7 years), longer for ergots (2.7 years), and longest for analgesics (codeine, barbiturates, caffeine combinations) ( 4.8 years) ${ }^{28}$

The frequency of use for drugs implicated in $\mathrm{MOH}$ varies from country to country and is influenced by multiple factors. ${ }^{4}$ Butalbital is commonly overused in the United States, while simple analgesics and caffeine-containing drugs are most commonly associated with $\mathrm{MOH}$ in other parts of the world (eg, Spain and Brazil). ${ }^{18,29}$ Until the mid 1990s, combination analgesics with codeine or caffeine, or ergots combined with caffeine were the most frequently overused drugs associated with $\mathrm{MOH}$ in many European countries. ${ }^{30}$

With the introduction of triptans, the pattern of $\mathrm{MOH}$ may be changing. In a review of patients seen at a single headache center in the US from 1990 to $2005, \mathrm{MOH}$ secondary to ergotamine decreased while $\mathrm{MOH}$ secondary to triptans increased. ${ }^{31}$ It is often difficult to identify a single causal substance for $\mathrm{MOH}$, since many patients are overusing more than one drug. ${ }^{4,27}$

\section{Clinical features}

The development of $\mathrm{MOH}$ is typically preceded by an episodic headache disorder, typically migraine or tension-type headache, that has been treated with frequent and excessive amounts of acute symptomatic medications. ${ }^{10}$ In clinical practice, $\mathrm{MOH}$ often manifests as a headache that is present or develops upon awakening. ${ }^{10}$

The severity, location and type of head pain can vary significantly among different individuals, but headache 
commonly occurs daily or nearly daily. ${ }^{10}$ Nausea, asthenia, difficulty concentrating, memory problems and irritability can accompany. ${ }^{10}$ To some extent, the clinical features may depend upon the type of headache medication that is overused. ${ }^{32}$

\section{Diagnosis}

The diagnosis is based upon clinical impression. A history of analgesic use averaging more than two to three days per week in association with chronic daily headache supports the diagnosis. The diagnosis is made when there is a pattern of frequent headaches that fulfill diagnostic criteria for $\mathrm{MOH}$.

\section{Diagnostic criteria}

The International Classification of Headache Disorders 2nd edition (ICHD 2) diagnostic criteria for $\mathrm{MOH}$ were published in $2004^{33}$ and revised in $2006 .{ }^{34}$ The revised criteria are as follows (Table-I).

Table-I

\section{The revised diagnostic criteria for $\mathrm{MOH}^{33}$}

A. Headache present on $>15$ days a month

B. Regular overuse for more than three months of one or more acute/symptomatic treatment drugs:

1 Ergotamine, triptans, opioids, or combination analgesic medications on $>10$ days a month on a regular basis for more than three months

2 Simple analgesics or any combination of ergotamine, triptans, analgesic opioids on $>15$ days a month on a regular basis for more than three months without overuse of any single class alone

C Headache has developed or markedly worsened during medication overuse

Note that "overuse" is defined by the frequency of medication treatment, and the criteria for overuse are specific for the type of medication being overused ${ }^{10}$.

\section{Differential diagnosis:}

Any form of chronic daily headache, whether primary or secondary, needs to be considered in the differential diagnosis. A high frequency of drug intake does not mean that $\mathrm{MOH}$ is the only headache disorder that is present. ${ }^{4}$ Typically, the patient has an underlying primary headache disorder.

\section{Treatment}

Withdrawal of the overused medication as soon as possible is the treatment of choice. ${ }^{35}$ Withdrawal of overused acute medications can be accomplished on an outpatient or inpatient basis. ${ }^{36} \mathrm{MOH}$ treatment involves four steps (Table-II)

Table-II

Treatment steps

1. Completely (100\%) wean off overused medications

2. Establish preventive medication and/or behavioral or nondrug preventive strategies

3 Provide acute medications with limits to prevent further overuse

4 Educate patient and family

It is also important to educate patients about the detrimental effects of analgesic overuse. Bridge (transitional) therapy may be useful during drug withdrawal to provide symptomatic relief. For most patients, a preventive (prophylactic) medication aimed at the suspected background primary headache disorder. An evaluation of the patient's $\mathrm{MOH}$ based on the duration and severity of the headache attacks, the number of overused medications consumed and their doses and comorbid medical and psychiatric conditions is necessary to formulate a treatment plan (Table-III).

Table-III

\section{Treatment options}

$>$ Out patients alone

$>$ Infusion therapy : out-patient \& in-patient

$>$ Integrated program:Day hospital \& In-patient program

$>$ All of the above with or without Onabotulinumtoxin A (Botulinum toxin type A)

In every patient with rebound, physicians should address the wean up front in the first steps taken. Prevention and wean should be added at the same time. There are four levels of wean (Table-IV).

Table-IV

Four levels of wean

1. Conventional out-patient: slow wean simultaneous Onabotulinum toxin A

2. Conventional out-patient with quick wean with bridge medications

3 Medical model : Infusion as the bridge with quick OnabotulunumtoxinA

4 Multidisciplinary program : day hospital and inpatient wean. 
Initiation, or slow addition of preventive medications; migraine-specific acute medications provided with strict limits. Initiation, or preventive medications (bridge with no tapering of rebound medications). Initiation or preventive medications either in infusion suite or inpatient. Multidisciplinary team using infusions as the bridge and quick OnabotulinumtoxinA initiation or preventive medications

\section{References}

1. Bahra A, Walsh M, Menon S, Goadsby PJ. Does chronic daily headache arise de novo in association with regular use of analgesics? Headache 2003; 43: 179-90.

2. Wilkinson SM, Becker WJ, Heine JA. Opiate use to control bowel motility may induce chronic daily headache in patients with migraine. Headache 2001; 41: 303-9.

3. Mathew NT, Kurman R, Perez F. Drug induced refractory headache-clinical features and management. Headache 1990; 30(10):634.

4. Diener HC, Limmroth V. Medication-overuse headache: a worldwide problem. Lancet Neurol 2004; 3(8): 475.

5. Scottish Intercollegiate Guidelines Network, 2008. 107: Diagnosis and management of headache in adults. A national clinical guideline. www.sign.ac.uk/ pdf/sign107.pdf.

6. Joint Formulary Committee. British National Formulary. Edition 58. London: BMJ Group and RPS Publishing, September 2009.

7. Katsarava Z, Jensen R. Medication-overuse headache: where are we now? Curr Opin Neurol 2007; 20(3):326.

8. Paemeleire K, Bahra A, Evers S, Matharu MS, Goadsby PJ. Medication-overuse headache in patients with cluster headache. Neurology 2006; 67(1): 109.

9. Young WB, Silberstein SD. Hemicrania continua and symptomatic medication overuse. Headache 1993; 33(9):485.

10. Dodick D, Freitag F. Evidence-based understanding of medication-overuse headache: clinical implications. Headache 2006; Nov 46; Suppl 4:S202.

11. Steiner T, 2010. Guidelines for all healthcare professionals in the diagnosis and management of migraine, tensiontype, cluster and medication-overuse headache. $3^{\text {rd }}$ edition. http://216.25.88.43/ upload/NS_BASH/BASH_ guidelines_2010.pdf.

12. Katsarava Z, Fritsche G, Muessig M, Diener HC, Limmroth V. Clinical features of withdrawal headache following overuse of triptans and other headache drugs. Neurology 2001 Nov 13; 57(9):1694-98.

13. Saper JR, Hamel RL, Lake AE 3rd. Medication overuse headache $(\mathrm{MOH})$ is a biobehavioural disorder. Cephalalgia $2005 ; 25(7): 545$.
14. Zwart JA, Dyb G, Hagen K, Svebak S, Holmen J. Analgesic use: a predictor of chronic pain and medication overuse headache: the Head-HUNT Study. Neurology 2003 Jul 22; 61(2):160.

15. Stovner Lj, Hagen K, Jensen R, Katsarava Z, Lipton R, Scher A et al. The global burden of headache: a documentation of headache prevalence and disability worldwide. Cephalalgia2007;27(3):193-210.

16. Zeeberg P, Olesen J, Jensen R. Probable medication-overuse headache: the effect of a 2-month drug-free period. Neurology2006;66(12):1894-98.

17. Diener H-C, Katasarva Z. Analgesic/abortive overuse and misuse in chronic daily headache. Curr Pain Headache Rep2001;5(6):545-50.

18. Pascual J, Colás R, Castillo J. Epidemiology of chronic daily headache. Curr Pain Headache Rep 2001; 5(6):529.

19. Diener, HC, Tfelt-Hansen, P. Headache associated with chronic use of substances. In: Olesen, J, Tfelt-Hansen, P, Welch, KMA (Eds). The Headaches, New York: Raven Press;1993. P.721.

20. Zwart JA, Dyb G, Hagen K, Svebak S, Stovner LJ, Holmen J. Analgesic overuse among subjects with headache, neck, and low-back pain. Neurology 2004; 62(9):1540.

21. Castillo J, Muñoz P, Guitera V, Pascual J. Kaplan Award 1998. Epidemiology of chronic daily headache in the general population. Headache 1999; 39(3):190.

22. Diener, HC, Limmroth, V, Katsarava, Z. MedicationOveruse Headache. In: Goadsby, PJ, Dodick, DW (Eds). Chronic daily headache for clinicians, Ontario: Decker Hamilton; 2005: 117.

23. Obermann M, Katsarava Z. Management of medicationoveruse headache. Expert Rev Neurother 2007; 7(9): 1145.

24. Bigal ME, Serrano D, Buse D, Scher A, Stewart WF, Lipton RB. Acute migraine medications and evolution from episodic to chronic migraine: a longitudinal populationbased study. Headache2008;48(8):1157-68.

25. Bigal ME, Serrano D, Buse D, Scher A, Stewart WF, Lipton RB. Acute migraine medications and evolution from episodic to chronic migraine: a longitudinal populationbased study. Headache 2008; 48(8):1157.

26. Bigal ME, Lipton RB. Excessive acute migraine medication use and migraine progression. Neurology 2008; 71(22): 1821 .

27. Bigal ME, Rapoport AM, Sheftell FD, Tepper SJ, Lipton RB. Transformed migraine and medication overuse in a tertiary headache centre-clinical characteristics and treatment outcomes. Cephalalgia 2004; 24(6):483.

28. Limmroth V, Katsarava Z, Fritsche G, Przywara S, Diener HC. Features of medication overuse headache following overuse of different acute headache drugs. Neurology 2002; 59(7): 1011 . 
29. Diener, HC, Limmroth V, Katsarava, Z. Medication. Overuse Headache. In: Goadsby, PJ, Dodick, DW (Eds). Chronic daily headache for clinicians. Ontario: Decker Hamilton; 2005: 117.

30. Meskunas CA, Tepper SJ, Rapoport AM, Sheftell FD, Bigal ME. Medications associated with probable medication overuse headache reported in a tertiary care headache center over a 15-year period. Headache 2006; 46(5):766.

31. Limmroth V, Katsarava Z, Fritsche G, Przywara S, Diener HC. Features of medication overuse headache following overuse of different acute headache drugs. Neurology 2002 Oct $8 ; 59(7): 1011$
32. Headache Classification Subcommittee of the International Headache Society. The International Classification of Headache Disorders: 2nd edition. Cephalalgia 2004; 24 Suppl 1:9.

33. Headache Classification Committee, Olesen J, Bousser MG, Diener HC, Dodick D, First M, Goadsby PJ,et al. New appendix criteria open for a broader concept of chronic migraine. Cephalalgia 2006; 26(6):742.

34. Diener HC, Limmroth V. Medication-overuse headache: a worldwide problem. Lancet Neurol 2004; 3(8):475.

35. Boes CJ, Black DF, Dodick DW. Pathophysiology and management of transformed migraine and medication overuse headache. Semin Neurol 2006; 26(2):232. 